\title{
Enhanced Ryanodine-Mediated Calcium Release in Mutant PS1-Expressing Alzheimer's Mouse Models
}

\author{
GRACE E. STUTZMANN, ${ }^{a}$ IAN SMITH, ${ }^{b}$ ANTONELLA CACCAMO, ${ }^{b}$ \\ SALVATORE ODDO,${ }^{b}$ IAN PARKER, ${ }^{b}$ AND FRANK LAFERLA ${ }^{b}$ \\ ${ }^{a}$ Department of Neuroscience, Rosalind Franklin University of Medicine and \\ Science, The Chicago Medical School, Chicago, Illinois, USA \\ ${ }^{b}$ Department of Neurobiology and Behavior, University of California, Irvine, \\ California, USA
}

\begin{abstract}
Intracellular $\mathrm{Ca}^{2+}$ signaling involves $\mathrm{Ca}^{2+}$ liberation through both inositol triphosphate and ryanodine receptors $\left(I_{3} R\right.$ and RyR). However, little is known of the functional interactions between these $\mathrm{Ca}^{2+}$ sources in either neuronal physiology, or during $\mathrm{Ca}^{2+}$ disruptions associated with Alzheimer's disease (AD). By the use of whole-cell recordings and 2-photon $\mathrm{Ca}^{2+}$ imaging in cortical slices we distinguished between $\mathrm{IP}_{3} \mathrm{R}$ - and $\mathrm{RyR}$-mediated $\mathrm{Ca}^{2+}$ components in nontransgenic (non-Tg) and AD mouse models and demonstrate powerful signaling interactions between these channels. $\mathrm{Ca}^{2+}$-induced $\mathrm{Ca}^{2+}$ release (CICR) through RyR contributed modestly to $\mathrm{Ca}^{2+}$ signals evoked by photoreleased $\mathrm{IP}_{3}$ in cortical neurons from non-Tg mice. In contrast, the exaggerated signals in $3 \times \mathrm{Tg}-\mathrm{AD}$ and $\mathrm{PS1}_{\mathrm{KI}}$ mice resulted primarily from enhanced CICR through RyR, rather than through $I_{3} R$, and were associated with increased RyR expression levels. Moreover, membrane hyperpolarizations evoked by $\mathrm{IP}_{3}$ in neurons from $\mathrm{AD}$ mouse models were even greater than expected simply from the exaggerated $\mathrm{Ca}^{2+}$ signals, pointing to an increased coupling efficiency between cytosolic $\left[\mathrm{Ca}^{2+}\right]$ and $\mathrm{K}^{+}$channel regulation. Our results highlight the critical roles of RyR-mediated $\mathrm{Ca}^{2+}$ signaling in both neuronal physiology and pathophysiology, and point to presenilin-linked disruptions in $R y R$ signaling as an important genetic factor in AD.
\end{abstract}

KEYWORDS: IP3; endoplasmic reticulum; 2-photon; electrophysiology; calcium; Alzheimer; PS1; 3×Tg-AD; transgenic; ryanodine; cortex; neuron

Address for correspondence: Grace E. Stutzmann, Ph.D., Department of Neuroscience, Rosalind Franklin University of Medicine and Science, The Chicago Medical School, 3333 Green Bay Road, North Chicago, IL 60064. Voice: 847-578-8540; fax: 847- 578-8515.

grace.stutzmann@rosalindfranklin.edu

Ann. N.Y. Acad. Sci. 1097: 265-277 (2007). (C) 2007 New York Academy of Sciences.

doi: 10.1196/annals.1379.025 


\section{INTRODUCTION}

Neuronal $\mathrm{Ca}^{2+}$ signaling is tightly controlled to ensure proper operation of a myriad of $\mathrm{Ca}^{2+}$-dependent processes. ${ }^{1,2}$ Two major sources contribute to cytosolic $\mathrm{Ca}^{2+}$ signals; an extracellular pool entering through plasma membrane channels, and an internal reservoir in the endoplasmic reticulum (ER) that is liberated by opening of inositol triphosphate- and ryanodinereceptor/channels $\left(\mathrm{IP}_{3} \mathrm{R}\right.$ and RyR). The activation of both $\mathrm{IP}_{3} \mathrm{R}$ and RyR channels is promoted by cytosolic $\mathrm{Ca}^{2+}$, resulting in a regenerative process of $\mathrm{Ca}^{2+}$-induced $\mathrm{Ca}^{2+}$ release (CICR). ${ }^{3-5}$ The feed-forward action of $\mathrm{Ca}^{2+}$ to enhance its own release through $\mathrm{IP}_{3} \mathrm{R}$ and RyR introduces considerable complexity in $\mathrm{Ca}^{2+}$ signaling, and enables interactions between these different pathways.

Growing evidence implicates disruptions of $\mathrm{Ca}^{2+}$ signaling in the etiology of neurological diseases. ${ }^{6-8}$ In particular, mutations in presenilin $(P S)$ genes associated with Alzheimer's disease (AD) increase $\mathrm{IP}_{3} \mathrm{R}$-evoked $\mathrm{Ca}^{2+}$ release in a variety of cells. ${ }^{9-11}$ Previous studies focused on responses evoked by elevating intracellular $\mathrm{IP}_{3}$ either directly via flash photolysis of caged $\mathrm{IP}_{3}{ }^{10,11}$ or indirectly by agonist application,,${ }^{9,12}$ and did not explicitly address the role of RyR in AD. Nevertheless, there is evidence pointing to RyR involvement. RyR expression levels are increased in cultured neurons expressing the PS $1_{\mathrm{M} 146 \mathrm{~V}}$ mutation, ${ }^{13,14}$ the RyR blocker dantrolene has been shown to reverse the elevated carbachol-induced $\mathrm{Ca}^{2+}$ release seen in SH-SY5Y cells expressing a mutant $P S 1,{ }^{15}$ and the RyR agonist caffeine evokes larger $\mathrm{Ca}^{2+}$ liberation in cultured neurons from transgenic $\mathrm{AD}$ mouse models. $^{14}$

Here, we explore RyR involvement in neuronal functioning in both normal physiology, and during $\mathrm{Ca}^{2+}$ signaling disruptions associated with $\mathrm{AD}$. For the latter purpose we employed two mouse models of AD: the $P S 1_{M 146 V}$ mutant knockin, and a triple-transgenic mouse model $(3 \times \mathrm{Tg}$-AD) $) .{ }^{16}$ Both transgenic mice display similarly exaggerated neuronal $\mathrm{Ca}^{2+}$ signals to $\mathrm{IP}_{3}$ at all ages, but whereas the PS1 $1_{\mathrm{KI}}$ mice fail to show AD histopathology, the $3 \times \mathrm{Tg}-\mathrm{AD}$ mice develop $\beta \mathrm{A}$ plaques and neurofibrillary tangles in an age- and a region-specific manner. We show that RyR activation contributes modestly to $\mathrm{Ca}^{2+}$ signals in nontransgenic (non-Tg) control mice, but accounts for almost all of the exaggerated $\mathrm{ER} \mathrm{Ca}^{2+}$ signals in the PS1 $1_{\mathrm{KI}}$ and $3 \times \mathrm{Tg}$-AD transgenic mice models. Moreover, in all groups, $\mathrm{IP}_{3}$-dependent membrane hyperpolarizations are regulated primarily through RyR, and the transgenic mice show hyperpolarizing responses even greater than expected from the enhanced $\mathrm{Ca}^{2+}$ signals. Thus, RyR contribute largely to the exaggerated $\mathrm{Ca}^{2+}$ signals associated with $\mathrm{AD}$-linked mutations in presenilin, and may thereby present a target for therapeutic intervention. 


\section{RESULTS \\ Exaggeration of $\mathrm{IP}_{3}$-Evoked $\mathrm{Ca}^{2+}$ Signals in $\mathrm{PS1}_{\mathrm{KI}}$ and $3 \times$ Tg-AD Neurons}

Individual neurons were loaded with caged I $\mathrm{P}_{3}$ and fura- 2 by dialysis through the patch pipette, and flashes of UV light of varying durations were applied to photorelease $I P_{3}$. The resulting ER Ca ${ }^{2+}$ liberation was monitored by imaging fura- 2 fluorescence from the soma (excluding the nucleus) and the proximal dendrites using a custom-built 2-photon imaging system, and by measuring changes in membrane potential resulting from activation of $\mathrm{Ca}^{2+}$-dependent $\mathrm{K}^{+}$channels. In addition, depolarizing current pulses were applied to evoke action potentials and accompanying entry of $\mathrm{Ca}^{2+}$ through VGCC.

FIGURE $1 \mathrm{~A}$ presents a scatter pl ot of individual I $\mathrm{P}_{3}$-evoked responses evoked by selected flash durations, and FIGURE $1 \mathrm{~B}$ plots the mean amplitude of these responses as a function of flash duration (proportional to the amount of photoreleased $\mathrm{IP}_{3}$ ) in the soma. The mean $\mathrm{Ca}^{2+}$ responses in $\mathrm{PS}_{\mathrm{KI}}$ and $3 \times \mathrm{Tg}-\mathrm{AD}$ neurons were appreciably $(P<0.05)$ larger than in non-Tg control cells for all flash durations, with the greatest enhancement seen with 30 ms flashes (316\% for $\mathrm{PS} 1_{\mathrm{KI}}$ and $342 \%$ for $3 \times \mathrm{T}$ g-AD neurons); but were not significantly different from one another. In marked contrast, no significant differences in spike-evoked $\mathrm{Ca}^{2+}$ signals were apparent between non-Tg, $\mathrm{PS} 1_{\mathrm{KI}}$, and $3 \times$ Tg-A D groups $(P=0.24)$.

\section{Enhanced RyR-Mediated $\mathrm{Ca}^{2+}$ Release Predominates in ER-Ca ${ }^{2+}$ Dysregulation}

To ascertain the extent of the RyR-mediated component in the IP $\mathrm{P}_{3}$-evoked $\mathrm{Ca}^{2+}$ signals, we first determined the relative RyR contribution by comparing somatic signals evoked by photoreleased IP 3 (FIG. 2 A, B) before and after bath-applying $10 \mu \mathrm{M}$ dantrolene to block RyR. In non-Tg neurons dantrolene caused a modest $(20 \pm 7 \%, n=6)$ reduction in signals evoked by 50 ms flashes, and action potential-evoked $\mathrm{Ca}^{2+}$ signals were reduced by $15 \pm 5 \%$. In marked contrast, dantrolene substantially reduced the $\mathrm{IP}_{3}$-evoked $\mathrm{Ca}^{2+}$ responses in $\mathrm{PS}_{\mathrm{K} \text { । }}$ neurons (by $59 \pm 11 \%, n=6 ; P<0.01$ ) and in $3 \times \mathrm{Tg}-\mathrm{A} \mathrm{D}$ neurons (by $71 \pm 9 \%, n=7 ; P<0.01)$. However, similar to non-Tg neurons, dantrolene produced only modest (15-20\%) reductions of the spike-evoked $\mathrm{Ca}^{2+}$ signals.

The effects of dantrolene on the dose-response relationship for IP $\mathrm{P}_{3}$-evoked $\mathrm{Ca}^{2+}$ signals are shown in Figure $2 \mathrm{C}$. Responses in $\mathrm{PS} 1_{\mathrm{KI}}$ and $3 \times \mathrm{Tg}-\mathrm{AD}$ neurons were not significantly different from one another $(P>0.05)$, and we therefore combined these data $(\mathrm{Tg})$ for analysis. Dantrolene strongly suppressed $\mathrm{Ca}^{2+}$ signals in the pooled Tg neurons $(n=19)$ across the full range 
(A)

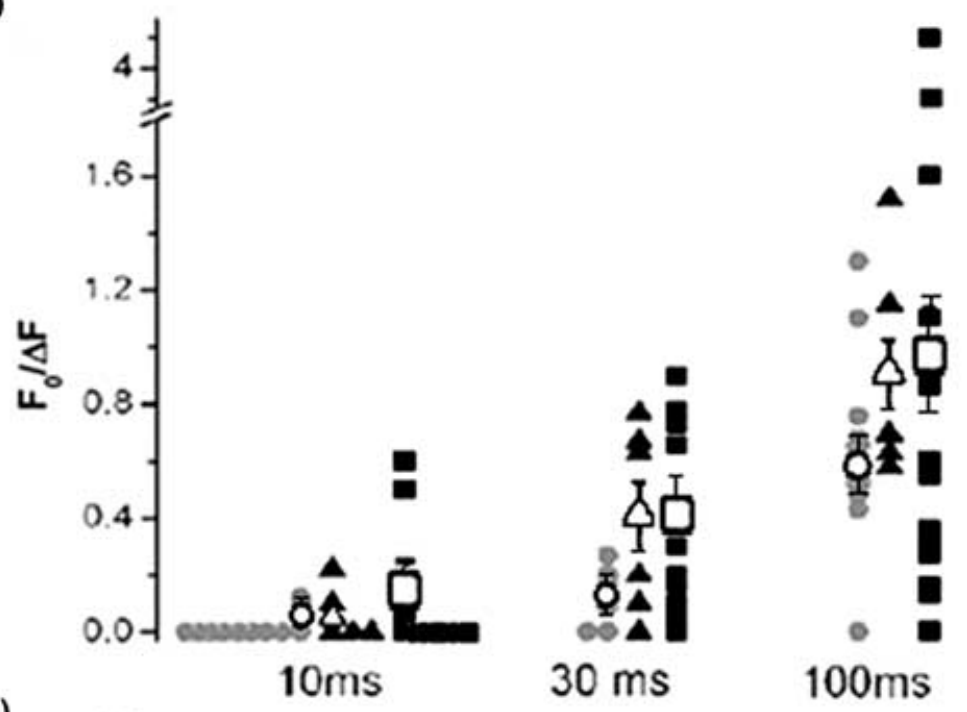

(B)

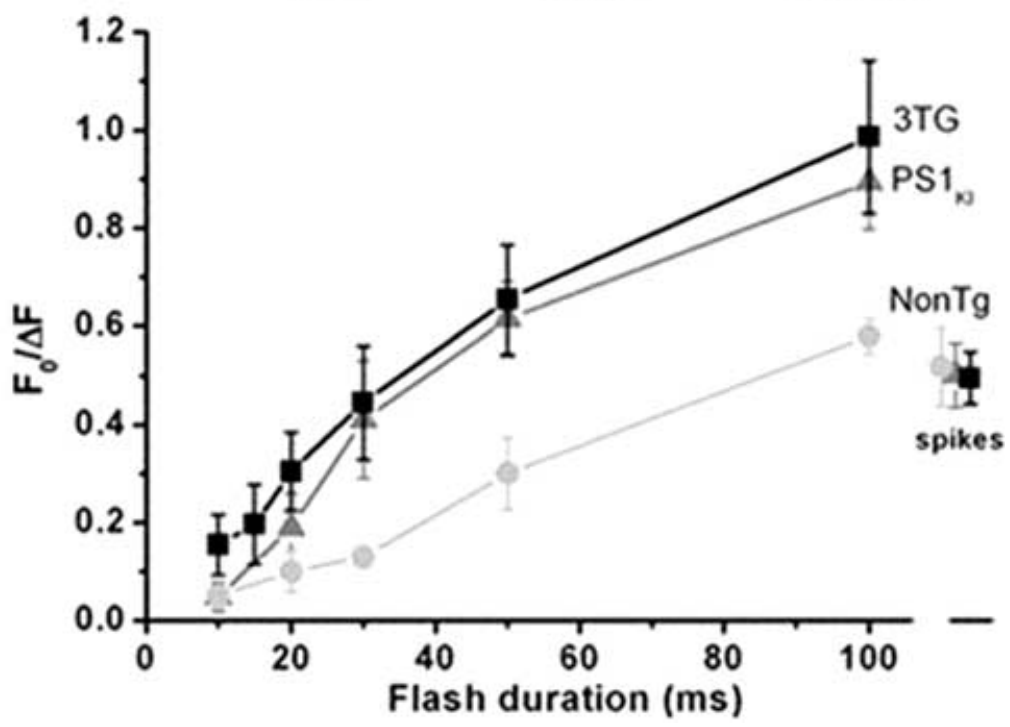

FIGURE 1. IP 3 -evoked $\mathrm{Ca}^{2+}$ signals are exaggerated in both $\mathrm{PS} 1_{\mathrm{KI}}$ and $3 \times \mathrm{Tg}$-AD mice. (A) Peak amplitudes of $\mathrm{IP}_{3}$-evoked somatic $\mathrm{Ca}^{2+}$ signals evoked by photolysis flash durations of 10,30 , and $100 \mathrm{~ms}$ in individual non- $\mathrm{Tg}$ (circles), $\mathrm{PS} 1_{\mathrm{KI}}$ (triangles), and $3 \times \mathrm{Tg}$ $A D$ neurons (squares). Open symbols with error bars indicate corresponding means and standard errors. Average $\mathrm{PS}_{\mathrm{KI}}$ and $3 \times \mathrm{Tg}-\mathrm{AD} \mathrm{Ca}{ }^{2+}$ amplitudes were significantly $(P<$ 0.05 ) larger for the 30 and $100 \mathrm{~ms}$ flash durations relative to the non-Tg values. (B) M ean peak amplitudes of somatic $\mathrm{Ca}^{2+}$ signals as a function of photolysis flash duration; data are from 12-14 neurons for each group. Points at the right indicate mean $\mathrm{Ca}^{2+}$ signals evoked by action potential trains. Data from non-Tg mice are indicated by light-gray circles $(\odot)$, $\mathrm{PS}_{\mathrm{KI}}$ mice by dark-gray triangles $(\mathbf{\Delta})$, and $3 \times \mathrm{Tg}-\mathrm{AD}$ mice by black squares $(\mathbf{\square})$. 


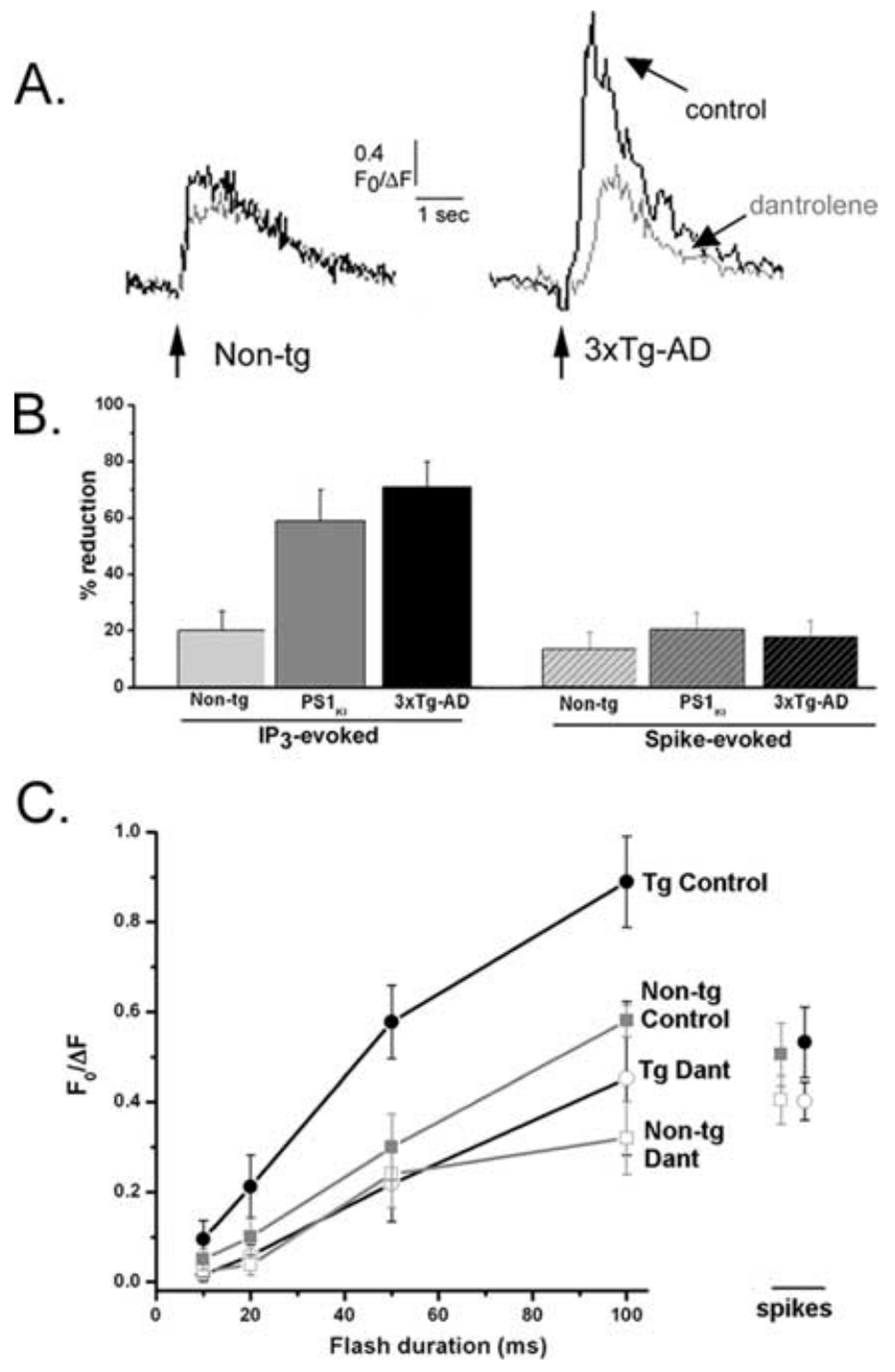

FIGURE 2. $\mathrm{Ca}^{2+}$ liberation through $\mathrm{RyR}$ contributes to the $\mathrm{IP}_{3}$-evoked $\mathrm{Ca}^{2+}$ signals. (A) IP 3 -evoked $\mathrm{Ca}^{2+}$ signals are reduced by the RyR blocker dantrolene. Traces show $\mathrm{Ca}^{2+}$ responses evoked by a 50 ms flash in control conditions (black) and in the presence of bathapplied dantrolene (gray), in representative non-Tg (left) and 3×Tg-AD (right) neurons. (B) M ean percentage reductions in amplitudes of $\mathrm{IP}_{3}$-evoked $\mathrm{Ca}^{2+}$ responses (50 ms flash duration) and spike-evoked $\mathrm{Ca}^{2+}$ signals resulting from application of dantrolene (10 $\left.\mu \mathrm{M}\right)$ in non-Tg $(n=6), \mathrm{PS}_{\mathrm{KI}}(n=6)$, and $3 \times \mathrm{Tg}-\mathrm{AD}(n=7)$ neurons. (C) Effect of dantrolene on the dose-response relationship of $\mathrm{IP}_{3}$-evoked $\mathrm{Ca}^{2+}$ signals. Points show measurements from non-Tg neurons ( $n=12$; squares) and pooled measurements from $3 \times \mathrm{Tg}-\mathrm{AD}$ and PS $1_{\mathrm{KI}}$ neurons ( $\mathrm{Tg}, n=25$, circles) before (filled symbols) and after (open symbols) applying dantrolene. $\mathrm{D}$ ata at the right show respective spike-evoked $\mathrm{Ca}^{2+}$ signals. 
of flash durations tested ( $F I G .2$ C; circles), whereas the reduction in non- $\mathrm{Tg}$ neurons $(n=6)$ was less pronounced (FIG. 2 C; squares). Importantly, there were no significant differences $(P>0.05)$ between $\mathrm{Tg}$ and non-Tg groups in the $\mathrm{Ca}^{2+}$ signals remaining in the presence of dantrolene, suggesting that $\mathrm{Ca}^{2+}$ flux through the $I P_{3} R$ channels themselves is not appreciably enhanced by the $A D$-linked mutations, but rather that larger responses in the Tg neurons arises principally from greater CICR through RyR. In contrast to the IP ${ }_{3}$-evoked $\mathrm{Ca}^{2+}$ signals, spike-evoked $\mathrm{Ca}^{2+}$ signals were reduced to a similar extent in both the non-Tg and $\mathrm{Tg}$ neurons.

\section{RyR Expression Levels Are Increased in Both PS1 ${ }_{K I}$ and $3 \times T g-A D$ Mice}

We performed Western blot analyses of several $\mathrm{Ca}^{2+}$ signaling-related proteins in the brains of non- $\mathrm{Tg}, \mathrm{PS}_{\mathrm{KI}}$, and $3 \times \mathrm{Tg}$-A D mice at ages (4-6 weeks) equivalent to those used in the imaging studies. There were no significant differences $(P=0.46)$ in cortical expression levels of IP $R$ R, SERCA-2B, calsenilin, calbindin-D, or cal reticulin (data not shown). H owever, RyR levels were significantly enhanced (FIG. 3; $\sim 2$-fold; A N OVA $F_{(2,8)}=9.41, P \leq 0.01$ ) in the $P S 1_{K I}$ and $3 \times T g-A D$ mice relative to non-Tg controls (Fischer post hoc analysis, $P=0.04$ and 0.005 , respectively). RyR levels in $P S 1_{K ।}$ and $3 \times T g-A D$ mice were not different from each other $(P=0.14)$.

\section{$I_{3}$-Evoked Membrane Hyperpolarization Is Driven by $\mathrm{Ca}^{2+}$ Liberation through $\mathrm{RyR}$}

$\mathrm{IP}_{3}$ evokes a membrane hyperpolarization in cortical neurons via activation of $\mathrm{Ca}^{2+}$-dependent $\mathrm{K}{ }^{+}$channels $\mathrm{s}^{17,18}$ and this hyperpolarization is enhanced in

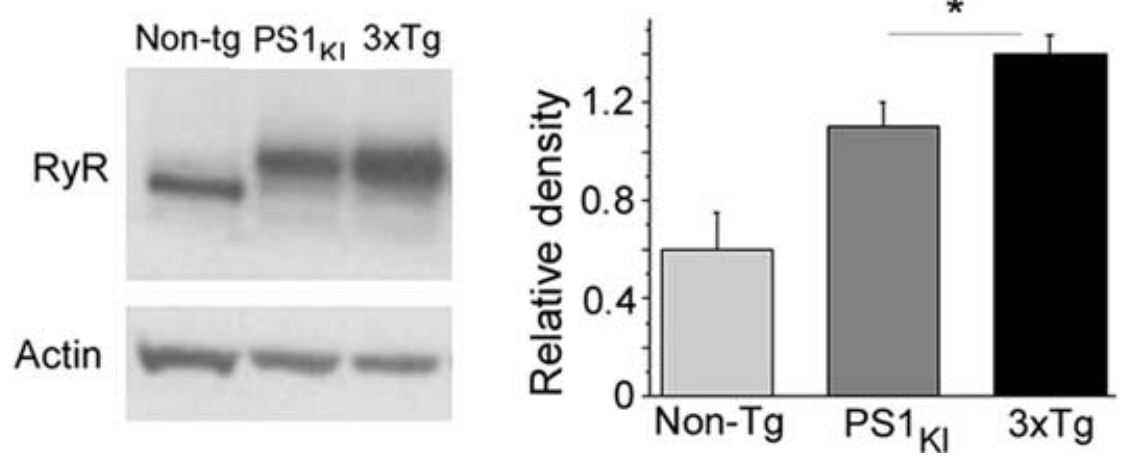

FIGURE 3. Tg neurons show enhanced expression of RyR and expression of mutant transgenes. Left: representative Western blots from homogenized non- $\mathrm{Tg}, \mathrm{PS} 1_{\mathrm{KI}}$, and $3 \times \mathrm{Tg}$ AD cortices demonstrating differences in RyR levels relative to $\beta$-actin. Right: RyR levels in the $P S 1_{\mathrm{KI}}$ and $3 \times \mathrm{Tg}-\mathrm{AD}$ mice were significantly greater ( $\sim 2$-fold) than non- $\mathrm{Tg}$ levels $(P<0.05)$, but were not different from each other. 
$P S 1_{K I}$ mice. ${ }^{18,19}$ Here, we sought to determine whether the $K^{+}$channel regulation primarily involves $C a^{2+}$ liberated through the $I P_{3} R$ channels themselves, or is consequent to CICR through RyR channels.

Representative membrane potential responses to photorel ease of $I P_{3}$ in non$\mathrm{Tg}$ and $3 \times \mathrm{Tg}-\mathrm{AD}$ neurons are shown in FIGURE $4 \mathrm{~A}$, and were appreciably smaller and of lower sensitivity in the non-Tg cells. These differences did not arise through differences in initial resting membrane potential (set to $-60 \mathrm{mV}$ by current injection) or input resistance. Strikingly, all responses

A.
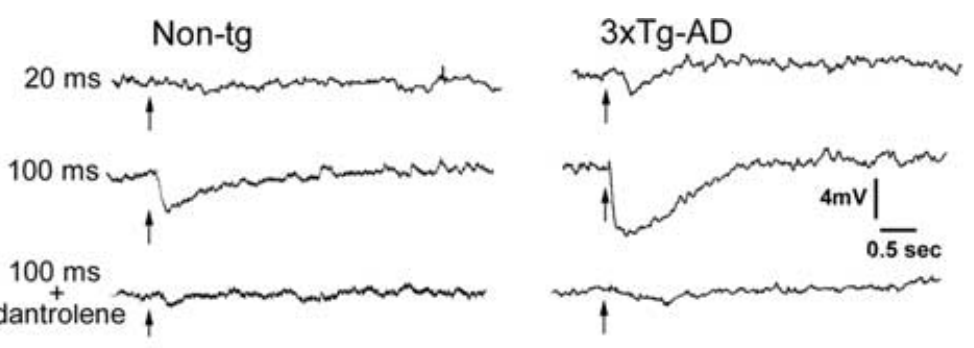

B.
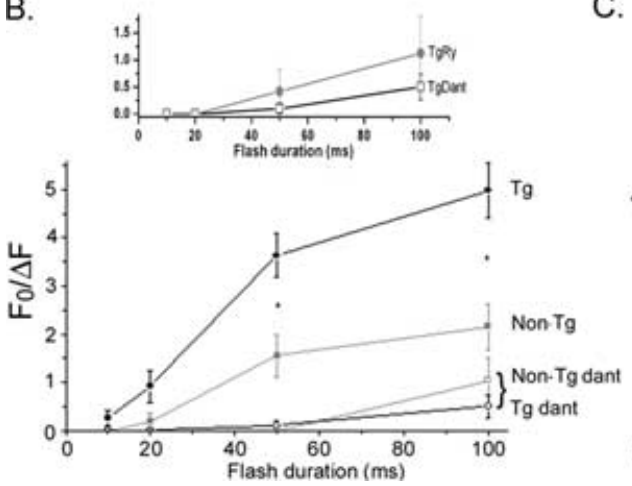

C.

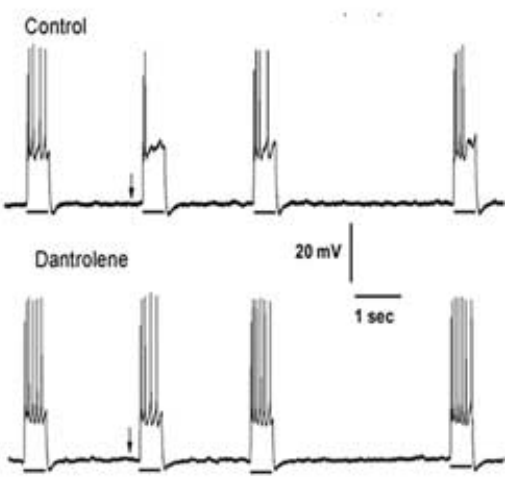

FIGURE 4. $I P_{3}$-evoked membrane hyperpolarizations are strongly suppressed by dantrolene. (A) Traces show (from top to bottom) changes in membrane potential in representative neurons from non-Tg (left) and 3×Tg-AD mice (right) following photolysis flashes of 20 and $100 \mathrm{~ms}$ duration, and the almost complete block of the response to a $100 \mathrm{~ms}$ flash in the presence of dantrolene $(10 \mu \mathrm{M})$. (B) Relationships between photolysis flash duration and magnitude of the $\mathrm{IP}_{3}$-evoked hyperpolarization. $\mathrm{M}$ ain graph shows data from non-Tg ( $n=17$, black squares) and Tg neurons ( $n=31$, gray circles), before (filled symbols) and during (open symbols) dantrolene application. Inset: M ean data comparing effects of ryanodine in Tg neurons ( $n=16$; closed circles) with dantrolene in Tg neurons (open squares, same data as in the main graph). (C) I $P_{3}$-mediated reduction in spiking frequency is suppressed by dantrolene. The upper trace shows spikes evoked by periodic injections of depolarizing current. A photolysis flash $(100 \mathrm{~ms})$ was delivered at the arrow to photorelease $I P_{3}$, resulting in a reduced spiking frequency for several seconds. The lower trace was obtained using the same protocol in the same neuron while continually superfusing dantrolene $(10 \mu \mathrm{M})$. 
were substantially abolished by dantrolene (FIG . 4 A, lower traces), even in the $3 \times \mathrm{Tg}-\mathrm{AD}$ neuron following a strong $(100 \mathrm{~ms})$ flash. M ean data for non- $\mathrm{Tg}$ and Tg neurons in control and dantrolene conditions are plotted in FIGURE 4 $B$. Hyperpolarizing responses in both non- $\mathrm{Tg}$ and $\mathrm{Tg}$ neurons increased with increasing photorel ease of $\mathrm{IP}_{3}$ but, for a given flash duration, the responses in Tg neurons were nearly three times as large (3.04-fold with 50 ms flashes, $P<$ 0.01 : and 2.7 -fold with 100 ms flashes, $P \leq 0.01$ ). A fter adding dantrolene, only small I $\mathrm{P}_{3}$-evoked hyperpolarizations remained with the strongest flashes, and were not significantly different between non-Tg and Tg neurons $(P>$ 0.05).

$\mathrm{IP}_{3}$-evoked changes in membrane conductance strongly regulate spiking patterns, and photorel ease of $\mathrm{IP}_{3}$ caused a long-lasting reduction in numbers of action potentials evoked by depolarizing current pulses (FIG. 4 C, upper trace). This modulation was abolished by dantrolene (FIG. 4 C, lower trace).

\section{AD-Linked Mutations Affect the Coupling between RyR and Membrane $\mathrm{K}^{+}$Channels}

The greater $I \mathrm{P}_{3}$-evoked membrane hyperpolarization seen in neurons expressing $A D$-linked mutations might arise directly as a consequence of the enhanced $E R \mathrm{Ca}^{2+}$ release. However, this appears not to be the sole mechanism, because scatter graphs plotting the relationship between $I \mathrm{P}_{3}$-evoked hyperpolarization amplitude $(-\Delta \mathrm{mV})$ and the accompanying $\mathrm{IP}_{3}$-evoked $\mathrm{Ca}^{2+}$ signals $\left(F_{0} / \Delta F\right)$ revealed markedly different slopes between non- $\mathrm{Tg}$ and $\mathrm{Tg}$ neurons for both soma (FIG. $5 \mathrm{~A}$ ) and dendrite (FIG. 5 B). That is to say, a given cytosolic $\mathrm{Ca}^{2+}$ signal was associated with a larger membrane hyperpolarization in Tg neurons, suggesting that the AD-linked mutations modulate the "coupling efficiency" between cytosolic $\mathrm{Ca}^{2+}$ signals and activation of membrane $\mathrm{K}{ }^{+}$ conductance, as well as enhancing the $\mathrm{Ca}^{2+}$ signals.

To explore the mechanism underlying this effect, we constructed a similar scatter plot of hyperpolarization versus $\mathrm{Ca}^{2+}$ signal amplitude after adding dantrolene to block RyR (FIG. 5 C). As noted before, both $\mathrm{Ca}^{2+}$ and membrane potential signals were strongly reduced, requiring pooled measurements from the soma and dendrite to obtain sufficient data points. Regression lines showed a slope for non-Tg neurons that was not appreciably different from that in control conditions without dantrolene, whereas in $\mathrm{Tg}$ neurons the slope was dramatically reduced as a result of blocking RyR. O ur findings are further summarized in FIGURE $5 \mathrm{D}$. Key points are: (1) The slope of the relationship between membrane hyperpolarization $(-\Delta \mathrm{V})$ and $\mathrm{Ca}^{2+}\left(\mathrm{F}_{0} / \Delta \mathrm{F}\right)$ was steeper (5.9) in Tg than in non-Tg neurons (3.15). (2) The slope in Tg neurons was greatly reduced by dantrolene, but was almost unchanged in non-Tg neurons. (3) The amplitudes of $\mathrm{IP}_{3}$-evoked $\mathrm{Ca}^{2+}$ signals (measured from the soma, averaged across all flash durations) in $\mathrm{Tg}$ neurons were approximately double that in 

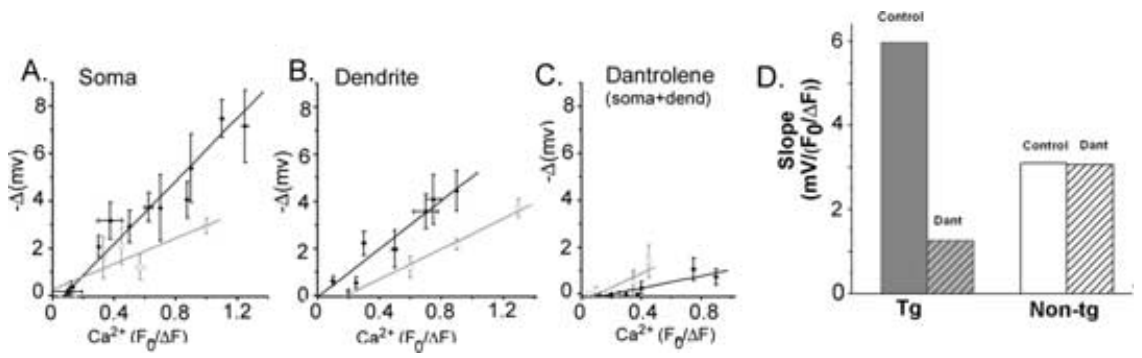

FIGURE 5. The relationship between the $\mathrm{IP}_{3}$-evoked $\mathrm{Ca}^{2+}$ signal and membrane hyperpolarization is steeper in Tg than in non-Tg neurons. (A) Scatter plot showing the relationship between $\mathrm{IP}_{3}$-evoked $\mathrm{Ca}^{2+}$ signal in the soma and the magnitude of the accompanying membrane hyperpolarization in neurons from non-Tg mice $(n=14$; open symbols, gray line) and Tg mice ( $n=23 ;$ closed symbols, black line). Points show means \pm 1 SEM obtained after binning over selected ranges of fluorescence amplitudes. (B) Corresponding data for measurements in the proximal dendrites. (C) Corresponding data in dantrolene $(10 \mu \mathrm{M})$, obtained after pooling data from soma and dendrites. (D) Dantrolene strongly reduces the slope of the relationship between $\mathrm{IP}_{3}$-evoked membrane hyperpolarization and $\mathrm{Ca}^{2+}$-fluorescence signal in $\mathrm{Tg}$ neurons, but has negligible effect in non-Tg neurons. Slope data were derived from the plots in (A, B, C).

non-Tg neurons, whereas membrane hyperpolarizations were more than three times larger. (4) Thus, RyR are critically involved in mediating the hyperpolarizing response evoked by IP 3 . M oreover, $A D$-linked mutations appear to result in greater hyperpolarizing responses not only because they enhance the $\mathrm{Ca}^{2+}$ signals, but also as a result of enhanced coupling efficiency between RyR and $\mathrm{Ca}^{2+}$-activated $\mathrm{K}+$ conductance.

\section{DISCUSSION}

\section{Involvement of RyR in IP ${ }_{3}$-Mediated Signaling in Neuronal Physiology and Pathophysiology}

The functional roles of intracellular $\mathrm{Ca}^{2+}$ stores in neuronal signaling are becoming increasingly recognized, and include modulation of membrane excitability, ${ }^{18,20}$ synaptic activity and plasticity, ${ }^{21}$ and gene transcription. ${ }^{22}$ To gain a more complete understanding of these intracellular $\mathrm{Ca}^{2+}$ signaling mechanisms we attempted to parse their $I P_{3} R$ and $R y R$ components so as to identify interactions between the two types of rel ease channel and determine functions that may specifically be coupled to a particular channel.

Here, we show that $\mathrm{Ca}^{2+}$ release evoked by $\mathrm{IP}_{3}$ in cortical neurons from non-Tg mice arises primarily from $\mathrm{Ca}^{2+}$ flux through $I \mathrm{P}_{3}$ receptors themselves, with a modest additional component being added by $\mathrm{Ca}^{2+}$ flux through $\mathrm{RyR}$. 
This balance, however, changes dramatically in transgenic mice expressing AD-linked mutations. Presenilin mutations are known to exaggerate ERmediated $\mathrm{Ca}^{2+}$ signaling in a variety of cell types, but this has implicitly been assumed to arise as a direct consequence of increased flux specifically through $I P_{3} R$ channels. ${ }^{9-11}$ Instead, our results demonstrate that $\mathrm{Ca}^{2+}$ flux through RyR accounts for the great majority of the exaggerated $I P_{3}$-evoked $\mathrm{Ca}^{2+}$ response in $\mathrm{AD}$ transgenic mice. Consistent with this, neurons from $A D$ transgenic mice showed larger $\mathrm{Ca}^{2+}$ signals in response to the RyR agonist caffeine, and enhanced expression of cortical RyR levels. Interestingly, in the $A D$ transgenic mice, the RyR component associated with VGCC activation was not different from the non- $\mathrm{Tg}$. Thus, the enhancement of $\mathrm{Ca}^{2+}$ signals by $A D$-linked mutations appears to arise primarily as a result of exaggerated $\mathrm{Ca}^{2+}$ flux through $R y R$ rather than through $I P{ }_{3} R$, and specifically affects $E R \mathrm{Ca}^{2+}$ signaling.

The RyR-mediated component of the intracellular $\mathrm{Ca}^{2+}$ signals al most certainly arises because CICR through RyR is triggered by, and amplifies, the $\mathrm{Ca}^{2+}$ liberated through IP $\mathrm{R}$. Increased expression of $\mathrm{RyR}$, as observed previously in cultured neurons ${ }^{13,14}$ and in the brains of mice expressing the $P S 1_{M} 146 \mathrm{~V}$ mutation, ${ }^{19}$ provides a likely explanation for the exaggerated $I \mathrm{P}_{3}$-evoked $\mathrm{Ca}^{2+}$ signals. M oreover, CICR may be further enhanced by the actions of PSI mutations to enhance $\mathrm{Ca}^{2+}$ filling of ER stores because el evated lumenal $\left[\mathrm{Ca}^{2+}\right]$ is known to increase the sensitivity of RyR to both cytosolic $\mathrm{Ca}^{2+}$ and caffeine. ${ }^{23,24} \mathrm{~A}$ lthough increased store filling might also be expected to result in greater $\mathrm{Ca}^{2+}$ flux through $\mathrm{IP}_{3} \mathrm{R}$-as has been observed in Xenopus 0ocytes, which lack $\mathrm{RyR}^{10}$ _our present results may be reconciled if $\mathrm{Ca}^{2+}$ stores in cortical neurons are enhanced sufficiently to sensitize RyR, while causing only a modest increase in $\mathrm{Ca}^{2+}$ flux through $I P_{3} R$. Q uestions remain, however, as to why the $\mathrm{Ca}^{2+}$ signals evoked by action potentials show relatively little RyRmediated contribution; and why there is no appreciable enhancement of these signals in the transgenic mouse models of AD. A n explanation may be that the voltage-gated $\mathrm{Ca}^{2+}$ channels in the plasma membrane are located more distantly from $R y R$ than are the $I P_{3} R$-channels, and are thus relatively ineffective in inducing CICR.

The mechanisms by which mutations in $P S$ expression result in RyR upregulation and exaggerated $E R \mathrm{Ca}^{2+}$ release are presently unclear. One explanation draws on evidence showing that the $P S$ mutations result in altered $\gamma$-secretase activity, which is responsible for the proteolysis of amyloid precursor protein (A PP). ${ }^{7}$ A PP proteolysis generates several fragments, including the A PP-intracellular domain fragment (AICD), which has been shown to regulate $\mathrm{IP}_{3}$-mediated $\mathrm{Ca}^{2+}$ signaling by possible transcriptional mechanisms. ${ }^{25,26}$ Although the target proteins ultimately affected are not known in this case, the AICD transcriptional activity may serve to influence expression or function of the RyR. 


\section{Electrical Excitability Is Modulated by RyR}

Intracellular $\mathrm{Ca}^{2+}$ plays an important role in modulating the electrical excitability of neurons, and A D-linked disruptions in $\mathrm{Ca}^{2+}$ might thus be expected to have acute consequences for neuronal signaling, as well as for chronic disease pathology. A ccordingly, we had found that hyperpolarizing responses to $I P_{3}$ are enhanced in $P S 1_{K I}$ neurons, ${ }^{11,19}$ probably because the enhanced cytosolic $\mathrm{Ca}^{2+}$ signals evoke greater activation of $\mathrm{Ca}^{2+}$-dependent membrane $\mathrm{K}^{+}$ channels. We now show a similar exaggeration of $I \mathrm{P}_{3}$-evoked hyperpolarizing responses in $3 \times \mathrm{Tg}-\mathrm{AD}$ neurons, and further demonstrate that in $3 \times \mathrm{Tg}-\mathrm{AD}$, $P S_{K 1}$, and non-Tg mice these membrane responses are mediated primarily by $\mathrm{Ca}^{2+}$ liberated through $\mathrm{RyR}$, rather than by the $\mathrm{Ca}^{2+}$ directly liberated through $I P_{3} R$. In particular, blocking of $R y R$ greatly reduced $I P_{3}$-evoked hyperpolarizations in both non-Tg and Tg neurons, resulting in al most identical membrane responses to a given flash duration.

The larger hyperpolarizing responses in the Tg neurons could most simply be accounted for as a direct consequence of the greater overall $\mathrm{Ca}^{2+}$ signal. However, this appears not to be the sole explanation, because the membrane responses accompanying $\mathrm{Ca}^{2+}$ signals of a given size were roughly twice as large in Tg versus non- $\mathrm{Tg}$ neurons: in other words, the $\mathrm{Tg}$ neurons showed a greater "coupling efficiency" between cytosolic $\mathrm{Ca}^{2+}$ and activation of $\mathrm{Ca}^{2+}$. dependent $\mathrm{K}^{+}$current. This may result if sites of $\mathrm{Ca}^{2+}$ liberation through $R y R$ are closer to the $C a^{2+}$-dependent $K+$ channels than are the sites of $I P_{3} R$ mediated $\mathrm{Ca}^{2+}$ liberation. On this basis, the disproportionate hyperpolarization in $\mathrm{Tg}$ neurons arises because most of their exaggerated $\mathrm{Ca}^{2+}$ signal arises through RyR; whereas after blocking RyR both $\mathrm{Tg}$ and non- $\mathrm{Tg}$ neurons show comparably small hyperpolarizations that are driven by the remaining $I P_{3} R$ mediated $\mathrm{Ca}^{2+}$ liberation.

\section{CONCLUSIONS}

Our results reveal important new aspects of $\mathrm{Ca}^{2+}$ signaling disruptions associated with $A D$. Specifically, exaggeration of $\mathrm{IP}_{3}$-evoked neuronal $\mathrm{Ca}^{2+}$ signals is principally linked to mutations in presenilin and is largely independent of expression of $A \beta$ plaques or neurof ibrillar tangles; these exaggerated signals are manifest throughout life and do not represent an accel eration of a normal aging process; and they arise principally through enhanced $\mathrm{Ca}^{2+}$ flux through $\mathrm{RyR}$, not $I P_{3} R$. Several crucial questions remain unanswered, including the mechanism by which mutations in presenilin modulate RyR-mediated signaling, and whether and how dysregulated $\mathrm{Ca}^{2+}$ signaling may play a causative role in $A D$ pathology. Nonetheless, these findings further strengthen the growing 
consensus that a calciumopathy may be at least partly responsible for neuronal degeneration in AD.

\section{REFERENCES}

1. Berridge, M., M. Bootman \& P. Lipp. 1998. Calcium—a life and death signal. Nature 395: 645-649.

2. BerRIDGE, M., P. LIPP \& M. B OOTMAN. 2000. The versatility and universality of calcium signaling. M ol. Cell Biol. 1: 11-21.

3. Finch, E., T. Turner \& S. Goldin. 1991. Calcium as a coagonist of inositol 1,4,5triphosphate-induced calcium release. Science 252: 443-446.

4. YAO, Y. \& I. PARKER. 1992. Potentiation of inositol trisphosphate-induced $\mathrm{Ca}^{2+}$ mobilization in $\mathrm{X}$ enopus oocytes by cytosolic $\mathrm{Ca}^{2+}$. J. Physiol. 458: 319338.

5. FRIEL, D.D. \& R.W. TSIEN. 1992. A caffeine- and ryanodine-sensitive $\mathrm{Ca}^{2+}$ store in bullfrog sympathetic neurones modulates effects of $\mathrm{Ca}^{2+}$ entry on $\left[\mathrm{Ca}^{2+}\right]_{i}$. . Physiol. 450: 217-246.

6. M ATTSON, M. et al. 2000. Calcium signaling in the ER: its role in neuronal plasticity and neurodegenerative disorders. TINS 23: 222-229.

7. LaFerLa, F.M. 2002. Calcium dyshomeostasis and intracellular signaling in A lzheimer's disease. Nat. Rev. N eurosci. 3: 862-872.

8. Stutzmann, G.E. 2005. Calcium dysregulation, IP 3 , signaling and Alzheimer's disease. Neuroscientist 11: 110-115.

9. Guo, Q. et al. 1996. Alzheimer's PS-1 mutation perturbs calcium homeostasis and sensitizes PC12 cells to death induced by amyloid beta-peptide. N euroreport 8: 379-383.

10. LeISSRING, M.A. et al. 1999. A lzheimer's presenilin-1 mutation potentiates inositol 1,4,5-trisphosphate-mediated calcium signaling in Xenopus oocytes. J. N eurochem. 72: 1061-1068.

11. Stutzmann, G.E. et al. 2004. Dysregulated IP 3 signaling in cortical neurons of knock-in mice expressing an A lzheimer's-linked mutation in presenilin1 results in exaggerated $\mathrm{Ca}^{2+}$ signals and altered membrane excitability. J. N eurosci. 24: 508-513.

12. EtcheberRigaray, R. et al. 1998. Calcium responses in fibroblasts from asymptomatic members of A Izheimer's disease families. N eurobiol. Dis. 5: 37-45.

13. Chan, S. et al. 2000. Presenilin-1 mutations increase levels of ryanodine receptors and calcium release in PC12 cells and cortical neurons. J. Biol. Chem. 275: 18195-18200.

14. SMITH, I. et al. 2005. Enhanced caffeine-induced $\mathrm{Ca}^{2+}$ release in the 3xTg-AD mouse model of A lzheimer's disease. J. Neurochem. 94: 1711-1718.

15. POPESCU, B. et al. 2004. Gamma-secretase activity of presenilin 1 regul ates acetylcholine muscarinic receptor-mediated signal transduction. J. Biol. Chem. 279: 6455-6464.

16. ODDO, S. et al. 2003. Triple-transgenic model of A Izheimer's disease with plaques and tangles: intracellular A beta and synaptic dysfunction. Neuron 39: 409421.

17. SAH, P. 1996. $\mathrm{Ca}^{2+}$-activated $\mathrm{K}+$ currents in neurones: types, physiological roles and modulation. TINS 19: 150-154. 
18. Stutzmann, G., F. LaFerla \& I. Parker. 2003. Ca $\mathrm{C}^{2+}$ signaling in mouse cortical neurons studied by two-photon imaging and photoreleased inositol triphosphate. J. Neurosci. 23: 758-765.

19. Stutzmann, G.E. et al. 2006. Enhanced ryanodine receptor recruitment contributes to $\mathrm{Ca}$ + disruptions in young, adult, and aged A Izheimer's disease mice. J. Neurosci. 26: 5180-5189.

20. Davies, P., D. IReland \& E. M CLaChlan. 1996. Sources of $C a^{2+}$ for different $\mathrm{Ca}^{2+}$-activated $\mathrm{K}+$ conductances in neurones of the rat superior cervical ganglion. J. Physiol. 495: 353-366.

21. NAKAMURA, T. et al. 2000. Inositol 1,4,5-triphosphate (IP 3$)$-mediated $\mathrm{Ca}^{2+}$ release evoked by metabotropic agonists and backpropagating action potentials in hippocampal CA 1 pyramidal neurons. J. Neurosci. 20: 8365-8376.

22. Mellstrom, B. \& J. Naranjo. 2001. M echanisms for $\mathrm{Ca}^{2+}$-dependent transcription. Curr. Opin. Neurobiol. 11: 312-319.

23. SHMIGOL, A. et al. 1996. Gradual caffeine-induced $\mathrm{Ca}^{2+}$ release in mouse dorsal root ganglion neurons is controlled by cytoplasmic and luminal $\mathrm{Ca}^{2+}$. Neuroscience 73: 1061-1067.

24. KoIZUM I, S. et al. 1999. Regulation of ryanodine receptor opening by lumenal $\mathrm{Ca}^{2+}$ underlies quantal $\mathrm{Ca}^{2+}$ release in PC12 cells. J. Biol. Chem. 274: 33327-33333.

25. CAO, X., T.C. Sudhof. 2001. A transcriptively active complex of APP with Fe65 and histone acetyl transferase Tip60. Science 293: 115-120.

26. LeISSRING, M . et al. 2002. A physiologic signaling role for the gamma-secretasederived intracellular fragment of A PP. Proc. Natl. A cad. Sci. 99: 4697-4702. 